\title{
Outfitting Textiles, Fashion and Architecture: the Convergence and Interplay of Construction and Engineering for the Human Form
}

\author{
Sarah E. Braddock Clarke
}

Fashion \& Textiles Institute, Falmouth University, Cornwall, UK

Telephone Landline: +44 (0) 1736741024 Telephone Mobile: +44 (0) 7967784723

Email: sarahe.braddock.clarke@falmouth.ac.uk

Sarah E. Braddock Clarke is a senior lecturer and a lead researcher at the Fashion \& Textiles Institute, Falmouth University. She has a particular interest in new textiles/technologies and their applications to fashion while encompassing a multidisciplinary approach, referencing areas such as architecture. She is co-author of many books on textiles and fashion, her latest being 'Digital Visions for Fashion + Textiles: Made in Code' published by Thames \& Hudson Ltd, 2012, UK and USA.

\begin{abstract}
Links between textiles, fashion and architecture are examined in terms of their visual aesthetics and methods of realization. Both garments and buildings touch our everyday lives and can be seen as similar types of "outfits." Pragmatic and expressive they provide protection and shelter while also reflecting taste and identity. As ever-new textiles and technologies are emerging these are infiltrating both the world of fashion, and that of architecture. Fashion references architecture, and architecture references fashion in human scale/proportions and harmony/balance of forms, while the correct choice of textile is crucial to their realization. Fashion is traditionally seen as being ephemeral and temporal and architecture as monumental and permanent but these notions are rapidly changing. Fashion is slowing down to embrace issues of sustainability, timelessness and longevity while architecture is speeding up to take on aspects of flexibility, mobility and change. It is proposed that the future will move towards a convergence that includes the bespoke where new textiles and technologies enable "outfits" to be made for wearing and for living in that are intimate and individual - tailored to suit and responsive to need.
\end{abstract}

\section{Keywords}

Textiles; fashion; architecture; construction; materials; technologies 


\section{Introduction}

The essence of what is required for the disciplines of textiles, fashion and architecture is clearly documented - that of providing protection and shelter principally by covering and cladding. What we wear close to us represents an innermost environment where a garment is an intimately designed object that (generally) involves a single body whereas a building (generally) involves several. You enter a garment, you enter a building and both are considered empty until the body inhabits. Fashion and architecture are co-related; human-centered and humanoriented they shape each other, dealing directly with aspects of anatomy, physiology, scale, proportion, motion and time. They are more akin than would first be thought.

Analysed here are practices that embrace textiles, fashion and architecture. A merging of textile-related decoration with architectural construction is posited by Driessen + van Deijne; site-specific interventions by Liminal demonstrate abstract notions of sensibilities between sound, space and textiles; a 'soft' form of architectural engineering is evidenced by the avant-garde fashion of Boudicca while the installations/performances of Maria Blaisse suggest that flexible materials and direct methods of construction can produce eloquent shape-shifting forms that link the body with interiors/exteriors. Figure 1.

The approach is one that concentrates on the power of the aesthetic and the sense of tactility where new expressions are possible due to advanced textiles and technologies. The chosen practitioners reflect the convergence of contemporary thought and creativity between textiles, fashion and architecture where concepts of mutability and the transitory are celebrated. Their output is viewed within a timeline that spans the 1950s to the present. Post World War II, numerous material and technological innovations made significant impacts with adaptable materials and 
inter-disciplinary techniques being favoured to enable forward-thinking arenas. The notion of "textiles" is in constant development where previously hard materials wood, metals, ceramics, plastics and resins - can become part of the repertoire due to their ability to morph between rigid and soft states. The library of such materials available to fashion designers and architects is ever-increasing in databases such as Material ConneXion.

Fashion is seen as being a creative expression as distinct from clothing for reasons of modesty/comfort where function is an over-riding factor. Aesthetically driven, fashion is an individual communication to the viewer of appearance and style choices that encompass the social and the cultural. Strong links between textiles, fashion and architecture are revealed in myriad forms by reflecting a society, its culture and era that, when displayed as choices, epitomize issues of identity and express taste. Taste, according to Pierre Bourdieu (1987) demonstrates underlying social structures. Our choice of wardrobe, our choice of dwelling defines and communicates ourselves, and our status.

There are certain key moments in time that have had a significant influence on fashion that can be seen as direct forms of cultural anthropology. In the 1950s youth questioned what their parents wore and rebelled against this by creating their own teenage fashions while Yves Saint Laurent was instrumental in bringing the city streets to the world of haute couture when he was head designer at the house of Dior in the late 1950s. Continuing, the 'youthquake' years of the 1960s showed similar inquiries and subsequent rebellions for Yves Saint Laurent's own label collections. Claude Lévi-Strauss put forward (1966) that class distinctions of this era were blurred and indistinct - the vintage and the contemporary being mixed in surprising ways for a bricolage of looks. Ideas of being unique, that wearing vintage enabled, are 
discussed by Georg Simmel who noted (Levine, 1972) that our desire to stand out and be noticed is frequently in conflict with our desire to fit in and be accepted. Fashion, with its constant need for change, creates a desire for nostalgia and a relation with the past; this same approach applies to listed buildings that must conform to guidelines, camouflaging into their surroundings instead of becoming distinctive landmarks.

Throughout history, examples of individuals who trained in architecture but moved into fashion include Pierre Balmain (1914-1982), Gianfranco Ferre (19442007), Pierre Cardin (1922-) and Tom Ford (1961-), with form remaining strongly evident in their work. In 2004 British Vogue fostered these links by commissioning collaborations between fashion designers and architects such as Hussein Chalayan with Foreign Office Architects (FOA) and Boudicca with David Adjaye. Previous distinctions are being shifted and eroded between the disciplines of textiles, fashion and architecture - moving closer towards convergence and coalescence; largely being due to the advent of new materials and technologies. Textiles are multi-versatile and can be applied in a variety of ways: fashion, products and architecture, both interiors and exteriors. They present potentials to be celebrated, embracing flexibility $-\mathrm{a}$ quality that can only be emphasized with advances in materials science. New forms of spatial morphologies enable previous transitions between two and three dimensions to be questioned and challenged. 3D printing enables construction directly in the round for bespoke and sustainable results.

The spheres of textiles, fashion and architecture possess symbiotic relationships that communicate personal, social, cultural, religious and political aspects through the strong connections maintained with our clothes and our homes. The practical and pragmatic exist while the outward expression of identities and aspirations is also clearly evidenced. 


\section{Façades, Claddings, Skins}

Building façades, claddings or "skins" are like new outfits where a fresh appearance can be given - a public "face." Material is placed over a form to exist on the uppermost surface and, when transparent or translucent, various interpenetrations and interactions are revealed. We clad ourselves and buildings are also clad - such coverings might radically alter and bend to our needs by taking on new colors, textures or forms depending on external influencing factors. This concept of "morphology" plays with tectonic strategies of transitions and transformations through insertions and extractions, fundamental to the way that many designers work.

Fashion and architecture deal primarily with the needs of the human body and its spatial considerations. In fashion, the body is clothed with a wide range of materials by cutting and constructing to fit, or draping and manipulating to envelop or, as is often the case, a mix of both methods that address the body. Furthermore, different cultures adopt different approaches; consider the traditional Western style where pieces of fabric are manipulated to closely follow contours contrasted with the traditional Eastern style where a single piece of fabric wraps for selvedge-to-selvedge dressing. In the former the fabric moves with the body while in the latter the body moves independently beneath. The Japanese even have a name for this threedimensional domain between the body and the garment - "ma." These days such approaches may still lie at the core of design but with our progressively mobile and global culture there is a distinct melding of the traditional with the contemporary.

Architects are increasingly using textiles for malleable solutions where membranes or skins are supported by structural frameworks for continuous exterior surfaces such as roofing systems. Likewise, what we wear is often discussed as a metaphorical "second skin." Terminology can be interchangeable between textiles, 
fashion and architecture: they have shared strategies and shared techniques and both linguistic and material comparisons exist. These include the outer "shell" of a building and a jacket; the "foundations" for the early stages of a build and the first items donned next to the body; "seaming" as joining mechanisms; "padding" as insulation; "layering" in next-to-skin, mid and outer layers and "web" as elemental interlacing. Shared techniques include cutting, creasing, folding, pleating, draping, scaffolding, cladding, suspending, hoisting, cantilevering, constructing, taping, fabricating, weaving, knitting, braiding, slashing, perforating, wrapping, tailoring, enveloping and lining. Construction, abstraction and reduction are concepts that have meaning in terms of the vision and the make of architecture and fashion where line is appropriate to each. "Structural" lines contour the basic form and are the main support and skeleton/scaffolding, such as in the "A-line" sheath dress. "Designer" lines work within these to give visual interest in the shape of pleats, tucks, gathers, seams and hems - elements that can be freely designed. Each technique can have many variations - pleats can be flared, concertinaed, mirrored, stretched, compressed, skewed and multiplied. "Additional” lines (horizontal, vertical, diagonal, curved) offer decoration and detail through various means such as print and embellishment.

Ornamentation through color, texture and pattern can add compositional value to distinguish space. Hil Driessen and Toon van Deijne of Driessen + van Deijne create striking patterns on buildings by working with digital technologies and a variety of substrates. "The Beacon of Ezinge", 2014 was designed by the duo for an education park (fine arts, design, music, theatre) by Atelier PRO architects in Ezinge, the Netherlands, where digitally printed glass is given rich imagery to enliven two façades of the tower in the community buildings (Driessen + van Deijne behance.net. ca. 2016). Figure 2. Within the crystalline structure can be seen gigantic 
florals and star constellations depicted in highly saturated colors. In order to realise this work and create strong reflections Driessen + van Deijne partnered with Si-X, a specialist in glass solutions. The process involved a digitally-transferred drawing that was printed with digital ceramic ink by Dip-Tech. These inks are specifically developed for glass substrates and contain sub-micron glass particles and inorganic pigments that, during the final hardening process blend with the glass itself - the decoration becoming part of the material structure. To further increase the intensity of the reflection a white backing was given to some of the colored areas. The artwork links directly to the purpose of the Ezinge complex as a place for creativity Rorschach spots were used alongside Spirograph patterns and then kaleidoscope photographed to create abstract forms that appear to be multiplying. The work of Driessen + van Deijne adopts an approach that merges disciplines, materials and technologies in oblique ways to defy the obvious. They continue to make scaled-down physical models to see their work imagined as 3D scenarios. Figure 3.

An onward trajectory is evidenced with the exhibition 'Intimate Architecture: Contemporary Design', Hayden Gallery, MIT, Cambridge, MA, 1982 that showed the work of eight fashion designers whose work linked to architectural form. This was the first fashion exhibition that MIT had staged and was highly successful, paving the way for fashion to be taken as a serious discipline, one worthy of academic appraisal. "Intimate Architecture" was instrumental to the concept of "Skin + Bones: Parallel Practices in Fashion and Architecture.” MOCA, Los Angeles, CA, 2006-2007 where forty architects and fashion designers were showcased, the focus being 1980-2006. "Skin + Bones," curated by Brooke Hodge, was a ground-breaking exhibition that made clear that aspects of tailoring and complex architectonics often have the same goals (Hodge, Mears and Sidlauskas, 2006). It is noted that "Intimate Architecture" 
was curated by Susan Sidlauskas who contributed to the catalogue of "Skin + Bones" showing a linked vision between the two, despite being twenty-five years apart. Both deal with the early 1980s but "Skin + Bones" continues, to evidence the incorporation of eminently flexible materials and advanced digital technologies that have enabled fluid and miniaturised components.

\section{Temporal, Ephemeral V Monumental, Permanent}

Fashion and architecture have traditionally worked to different timescales, days and years respectively, impacting on how they are conceived and perceived. However, today's architects are responding to diverse concepts such as "flat pack" and "dematerialization" to become more closely linked to the world of fashion, an approach that has altered their pace, where change is seen as both an inspiration and a challenge. Fashion has been criticized for being "fast" but the notion of "slow" is also being embraced, where a timeless elegance is sought and clothes kept for the next generation. Quality is being sought over quantity by sustainably-minded designers. The same is happening in the field of architecture where buildings are increasingly being restored rather than razed. Architecture is moving away from the permanent to the flexible where transition is a positive and not necessarily to be avoided.

Motion is linked to ideas of the ephemeral, and perhaps this applies more to fashion than architecture. A flexible form materializes and embodies movement, possessing dynamism as its wearer moves through space. A sense of transience is realised when circular cutting gives fluctuating arcs/curves; bias cutting creates jutting diagonals and pleating expands/contracts to show kineticism. Furthermore, clothes with drawstrings adjust - tightening to shorten, relaxing to lengthen, and tapes with fastening devices can create permutations of form. Patterns of successive growth in nature have long inspired practitioners - spiral forms where cells are a distance 
apart based on the Fibonacci sequence and the golden ratio conjures up the wellproportioned. Cecil Balmond of Arup Advanced Geometry Unit (AGU) stated: "Geometry advances when it is a movement for change, making a network rather than a static map. (...) And geometry advances when its connections and network are part of an evolving pattern, when it ceases to be static." (2007: Template 06). In architecture motion is implied where a visual rhythm is present in the exterior but also in the interior as inhabitants shape a space with their bodily presence. Movement is a quality that an architect often yearns for, finding ways of compensating for the static by capturing the fluidity of cloth in swooping forms, curving silhouettes, forward/upward projections or meandering transitions. The infinite loop of the Möbius strip has been explored in both clothing and architecture to wrap and encircle. Zaha Hadid's avant-garde commissions look as if they are constantly in flux - planes sharply intersect, fragmented forms turn and twist in space while unexpected projections and gravity-defying solids appear to float.

In terms of gravity there is a significant difference to the way such a force is worked with in garments and in buildings. In fashion most pieces fall in a downwards direction, acting with gravity and bearing loads that are usually suspended from shoulders/waist/hips; but sometimes those conventions are defied by supporting from elsewhere, as in any strapless garment - a true engineering feat. Draping fabric directly on a mannequin works with the weight of the cloth and how this reacts against the resistant form, dealing with the physics of hanging, falling, suspending. Buildings, on the other hand, traditionally have a connection to the verticality of the human stance by constructing upwards. However, buildings can camouflage with their environment where mirrored surfaces reflect surroundings or hide their volume 
by retreating underground. This invisibility is distinct from landmark architecture that generally reaches up to scrape the sky.

Marcos Novak states "Liquid architecture is an architecture that breathes, pulses, leaps as one form and lands as another." (Benedikt, 1992: 272). Describing himself as a "trans-architect" his work is responsive and invites viewer interaction. His three-dimensional constructions do not exist in the physical world but in the virtual where abstract qualities of sound are conjured up as habitats for immersive experience.

Liminal is the name for South-West (UK)-based Frances Crow and David Prior who use sound to articulate space and create works that relate strongly to the body and the senses. "Organ of Corti", 2010-2011 is a lattice of 4-metre high acrylic cylinders positioned in a way that is known as a "sonic crystal array" (Liminal liminal.org. ca. 2016). Acrylic, a synthetic material, can be highly flexible and used in clothing or semi-flexible as shown here. The title refers to the organ of hearing in the inner ear that translates physical movement of sound into the electrical impulses received by the brain. The sonic crystal accentuates and attenuates frequencies within the surrounding noises, creating subtle changes to a listener's perception of the source sound. The work itself does not create any noise but allows the listener to focus and closely engage with the real sounds that immediately encompass them, recycling these noises. "Organ of Corti" rematerializes the experience of hearing where the sounds themselves vary depending on where the listener is positioned within the installation. Figure 4.

In architecture, four important concepts and style tendencies are modernism, post-modernism, deconstructivism and minimalism. These have also been made manifest in textiles and fashion where a variety of tastes can be accommodated from 
the minimalists that adhere to Ludwig Mies van der Rohe's "less is more" (Mies Society.org ca. 2016) to the maximalists that follow Robert Venturi's "less is a bore" (Venturi Scott Brown.org ca. 2016).

Modernism is concerned with underlying structure and its inherent beauty, where proportions play an important part. Le Corbusier had his "Modulor" proportional system where the height of a ceiling in a building is that of a perfectly proportioned man with one arm outstretched. He devised a series of dimensions that related directly to the human body and carried these with him on a tape measure in his pocket. In the 1960s André Courrèges (who initially trained as a civil engineer) created streamlined clothing and was inspired by Le Corbusier. Based on rational thinking, where Louis Sullivan's “form follows function" (Artic.edu ca. 2016) ruled, modernism gave supremacy to purist values concerning line and form demonstrated in a clear, classical beauty that had an aversion to ornamentation. Pioneers, the modernists developed a style of utopian architecture - one that was austere, graphic and heavily functionalist, but with an over-riding balance and harmony.

Post-modernism puts forward an antithesis to this aesthetic where strange juxtapositions plunder the history of culture and hybrid forms are purposefully provocative. The post-modernists wanted to break free from the constraints of modernism and highly creative, post-modernist architects repudiated traditional ways of working (plan/section/elevation drawings) to create layered imagery and take on color. Typically, post-modernism celebrates popular culture where a world of signs and symbols is emblazoned on the skin of buildings and on the fabric of fashion. Such high-profile visibility can be seen in the Centre Georges Pompidou, Paris (1977) created by Renzo Piano and Richard Rogers that exposed the infrastructure, literally turning it inside out with conspicuous pipework and air ducts. Mechanisms were 
color-coded - ventilation systems were blue, electrical systems were yellow or orange and elements that allowed for movement were red - the escalators that formed a snaking diagonal tube on the exterior front were painted red on their underneath section. This building broke the rules of architecture and was a breath of fresh air.

Deconstructivism and minimalism both deal with reduction in form and are the movements that have possibly most impacted on fashion and architecture. Throughout the 1980s the emphasis given to deconstructivism's relationship to such areas resulted in new formal vocabularies that included fragmentation, abstraction and the seemingly unstable. Deconstruction as a critical analysis referenced punk of the mid to late 1970s and was a reaction against the sexualised aggression and overt power of the 1980s. Instead, a more cerebral approach was presented where ideas of disruption and dislocation created disturbed shapes. It was not a demolition, but instead forms were interrupted - taken apart and reassembled. This thinking with its ideologies, approaches and aesthetics that acutely clashed with previous theories, opened up design practice. Deconstruction was evidenced in the radical fashion of the Japanese avant-garde that came to the fore in the early 1980s. The place and date can be pinpointed to the International Hotel in Paris, April 1981 when Rei Kawakubo of Comme des Garçons and Yohji Yamamoto showed their ready-to-wear collections to an audience of around one hundred. The press were mostly shocked and responded accordingly with headlines of 'Hiroshima Chic', 'Le Destroy' and 'Karasu-zoku' (crow gang). These two designers experimented with asymmetric, oversized forms, rough textures took center stage and the palette was predominantly various shades of black. Rawness, the distressed, the undone, the unfinished were honored - fabrics were creased and crumpled; edges were ragged, tattered and shredded; hems were irregular; woven fabrics were frayed; knitted textiles were laddered; seams and darts 
were exposed; details (collars, lapels, pockets) were unconventionally placed; folds were mysterious and deliberate cut-outs revealed underlying flesh. Resulting forms defied the norm - shifting, distorting, displacing and puncturing.

A similar approach was also happening in architecture where deconstruction was visualised by a rustic and unpretentious aesthetic, explored in the 1988 exhibition 'Deconstructivist Architecture', MOMA, New York. Signatures of this style were unfinished mortar and imprints of the process of casting concrete being left behind without being smoothed over. Both interior and exterior aspects were also deliberately exposed. Rei Kawakubo and Frank Gehry are prime examples of deconstruction where a sample of crushed velvet or a crumpled paper bag might be employed to convey their concepts to colleagues who then had the task of attempting to realise such complex abstractions in tectonic ways.

Rei Kawakubo sees little distinction between her clothes and her stores describing them as “(...) which used untreated mortar. It was a finish which cracked as soon as it set, leaving hairline fractures running across floors and up walls $-\mathrm{a}$ deliberate denial of formal perfection (...)." (Sudjic, 1990: 114). Furthermore, Rei Kawakubo said in conversation with Tadao Ando "From the point of view of finding possibilities, architecture and clothes-making share many common potentials." (Sudjic, 1990: 10). In the mid 1970s Rei Kawakubo began a collaboration with Takao Kawasaki to develop a distinctive store identity. In Japan the inside and the outside are traditionally treated differently with the aim being to exclude the outside world, filtering any visual noise and providing a controlled stillness. In his book 'In Praise of Shadows' (1933/1934), an essay on aesthetics that centers on traditional Japanese culture, Jun'ichirō Tanizaki articulates "And so it has come to be that the beauty of a Japanese room depends on a variation of shadows, heavy shadows against light 
shadows - it has nothing else." (1977: 18). He discusses ideas of the momentary - the power of contrasts where the sun illuminates to cast shadows, the ambience of light and the clashing of tradition with technology. It is fitting that the foreword for the 1977 translated book is by Charles Moore from the School of Architecture at UCLA.

In the late 1980s and early 1990s there was a distinct return to the concepts of deconstruction with a group of Belgian fashion designers known collectively as the 'Antwerp Six' that again challenged traditions, turning fashion on its head. The late Bill Cunningham talking about the deconstruction of Martin Margiela, (a colleague of the 'Antwerp Six') and his Autumn/Winter 1989/1990 collection wrote:

Martin Margiela, formerly a Gaultier assistant, in this, his second collection on his own, provided quite a different version of fashion for the 1990s, a beatnik, Existentialist revival (...) The construction of the clothes suggests a deconstructivist movement, where the structure of the design appears under attack, displacing seams, tormenting the surface with incisions. All suggest a fashion of elegant decay. (1989: 246)

Then again, describing Martin Margiela’s Spring/Summer 1990 collection Bill Cunningham stated that he "Realized a brash new spirit exploding out of rap music and deconstructivist architectural impulses (...)” (1990: 180). In his commentaries, Bill Cunningham links the term 'deconstructivist' firmly with experimental fashion.

Minimalism is a distillation, a paring down to the essence where the simplest geometric shapes are often used for points of departure - squares, rectangles, cylinders and cones while construction elements supply any visual decoration. The clean Hellenic purity of a steel frame in the Teutonic manner of Ludwig Mies van der Rohe finds similar form in Phoebe Philo's silhouettes as creative director at Céline. 
Building on the concept of post-modernism's "paper architecture" (so-called as it remained within the theoretical) is "liquid architecture," the aforementioned phrase coined by Marcos Novak in the early 1990s (Benedikt, 1992: 272). Here, buildings exist only in the realm of the virtual - a truly minimalist domain where algorithmic techniques design forms that are in constant development and states of evolution.

\section{Materials, Technologies - Analog and Digital}

The 1850s saw the prefabrication of building materials where advances in steel construction enabled light and open structures - webs with glass panes, shown in the Crystal Palace at the Great Exhibition, London, 1851. Leaping ahead, seismic changes in material science within the last few decades have been undertaken, forging and enhancing connections between the areas of textiles, fashion and architecture. It is what the architects of "paper architecture" would have fully appreciated.

The 1960s fashion of Cristóbal Balenciaga frequently favored the sculptural, where textiles held their own with no need for additional support mechanisms. Materials that were employed were wide-ranging; most were inherently capable of maintaining shape and had a crispness or solidity, for example, the sheerness of silk gazar and taffeta and the denseness of structured wools. Furthermore, his designs referenced architectural form by creating spherical and trapezoidal shapes for the body to inhabit.

Post-modernist architects of the 1970s were heavily intellectual, and their radical and often over-optimistic ideas for cityscapes were unworkable due to a lack of appropriate materials and technologies. Then, during the 1980s there was a civic pride in the loftiest skyscrapers where each architect would attempt to outdo the other. This was especially so in America during the early 1980s, and examples include 
JPMorgan Chase Tower (1982), Houston, Texas, by architect I.M. Pei; 101 Park Avenue (1982), New York City, New York, by Eli Attia Architects, and One Magnificent Mile (1983), Chicago, Illinois, by architects Skidmore, Owings \& Merrill. In fashion terms these manifestations of status showed in the widths of shoulders, where so-called "power dressing" exuded ego while the borrowing of classical motifs for textiles frequently referenced Greek architecture.

Contemporary avant-garde label Boudicca's “The Invisible City” by Zowie Broach and Brian Kirkby showed their cerebral tailoring and meticulous craftsmanship that incorporated volumetric textiles for precise architectonic forms. (Boudicca - platform13.com. ca. 2016). Based on the novel "Invisible Cities" (1972) by Italo Calvino the collection referenced built form and classical architecture by using cutting, folding, pleating and layering to achieve bustled shapes that cantilevered away from the human body. Such extreme silhouettes contrasted with the formality of a suit that was also imbued. Figure 5 and Figure 6.

In the 21 st century a new creative language has been formed that deals with the visual, the tactile, the material and the technical. Engineering is at bio or nano level for responsive surfaces and dynamic structures that are specific-to-purpose with many taking on the sensory. Resulting malleable thermoplastics, super-fine and ultra-tough microfibers, featherweight skins and breathable membranes provide weatherproof systems for geometric/biomorphic forms to dress a body or a building. In addition, there is a strong move towards sustainable systems that use recycled/reclaimed materials. A synthesis is created where upcycling rewards the maker with an ethical product that can often, in turn, be further recycled.

Some architects appear to favor particular materials such as Tadao Ando whose clean lines and seeming weightlessness are conveyed in concrete and glass 
buildings, while certain fashion designers have a penchant for classic materials such as the double-face cashmeres of Albert Kriemler for Akris. There are also those who have challenged traditional ways of constructing - Paco Rabanne's linked and riveted clothing and Pierre Cardin's moulded and cast ready-to-wear, both from the 1960s, offered preludes for the future.

The warp and the weft of a constructed cloth bear the stresses and strains of loads exerted upon them but the engineering demands for a building and for a garment differ. In architecture it is generally important to ensure such pressures are uniform where fabric is generally stretched and held over a structure. Material advances have enabled stress to be distributed evenly when impacted in order to lessen any effects where a weaker area could pull, distort and ultimately yield and rupture as it reaches breaking point. In engineering there are three basic types of stress - tensile (causes lengthening), compressive (causes shortening) and shear (the maximum load before deformation occurs). Additionally, volumetric stress is where three mutually perpendicular stresses exert stress from different directions and torsional stress has a circular aspect and twists in space, displaying movement. In fashion such stresses can be held and supported in certain places while other areas are allowed to drape, relying on gravitational pull to deform. This approach gives scope for diversion from strict engineering principles where working around the body allows a freedom of expression. Research in surface/structure articulation has led to new capacities for stretch to enable products to have a propensity for being taut or relaxed - possessing a "give" as is often referred to in textiles/fashion. Equally important is "recovery" where an inherent memory allows an original form to be returned to. The recovery of a textile after being extended depends on the molecular bonding and crystalline structure of the fiber, together with the force of the extension. 
In architecture, one of the most significant stresses is an earthquake, and in the world's zones where these natural forces frequently occur buildings have been specifically designed to withhold their own by not necessarily choosing the traditional route of rigidity, but instead instilling elasticity into the fabrication to move with the force. Materials are selected that mutate, absorbing stresses and evenly distributing them in order to lessen subsequent damage.

Using a similar concept for fashion, bamboo, a truly flexible material is favored by Maria Blaisse for her "Moving Meshes" series, 2007-2008 where spherical constructions merge ideas of interior and exterior, involving the human body in dance improvisations. Maria Blaisse frequently references organic form to be found in nature such as spirals and spheres, exploring the potential for one form to become many by creating different configurations and utilizing materials that exude pliability. Her series 'Gauze Forms', 2005-2007 is made of polyester and blends the inside and the outside with its mesh-like structures where spiralling forms articulate and interlace to imply a sense of continuing movement. A wonderful moiré effect is seen where the skins overlap and interplay (Blaisse, Maria - mariablaisse.com. ca. 2016). In her research every aspect of the material and the structure have become available and no waste is produced. With these works Maria Blaisse has designed a one-form language and system that invites creative potential to be applied to products, fashion and architecture. Figure 7.

A correctly chosen material is fundamental to the success of a garment or a building but its application and articulation also need careful consideration. Precise engineering is often applied to working with textiles for fashion where seams bear weight and support stress points, just as beams that straddle walls do for buildings; while straps (in garments and buildings) anchor to distribute tensions. In both fashion 
and architecture the challenge often concerns gravity. One example is the bra that is based on the principle of a suspension bridge where cables bear weight and create arching forms. The 'balconette' bra design works by cantilevering and dealing with support and overhang. The wires and straps (where used) "lift and support" while managing the distribution of the weight within the bra to the band that runs around the torso. Both principles of suspension and cantilevering are extremely relevant to architecture and to fashion. Furthermore, methods of construction such as hanging stone on steel, discovered by Louis Sullivan, led to the Chicago skyscraper and the abolishment of "stone architecture" that was heavy and unresponsive. His previously stated 1896 axiom "form follows function" was taken on by practitioners across a myriad of disciplines.

Layering is a consideration that can create visual interest, but also more pragmatically can provide insulation where air is trapped between each subsequent covering. This has relevance for both fashion and architecture - we add or remove clothing as we move in and out of buildings; the aim being to maintain an even body temperature with the clothed body, and likewise for temperature-controlled, airconditioned built environments.

Advances in materials have coincided with advances in technologies to enable complex structures to be unbounded by straight lines and articulate space in hitherto unforeseen ways. Yokohama International Port Terminal (2002) is positioned on land that juts out into Tokyo Bay. Designed by FOA it celebrates the motion of trade and commerce at this port, once an important centre for Japan's silk industry. The structure, interlaced with ribbon-like, looping ramps, references origami folds. It is dynamic where multiple paths present walkers with options and the roof with its undulating "dunes" of wood planking gives changeable views. 
The Tokyo flagship Prada store (2003) designed by Herzog \& de Meuron is a five-sided, six-story building that resembles a gigantic crystal. A faceted skin has diamond-shaped glass panes (set in a steel frame) that vary between the flat, concave and convex, creating variable distortions of the reflected urban surroundings. Jacques Herzog has a personal interest in fashion, having being surrounded with textiles due to his mother's tailoring business. He is fascinated with what people wear and this is shown by his preoccupation with architectural cladding. By commissioning Herzog \& de Meuron to design the Prada Tokyo store, Miuccia Prada shows that the identity of the label is linked to avant-garde thinking in architecture.

When CAD/CAM began to be used widely in the architecture industry during the 1980s there was a distinct move away from physical model making. Instead, computer modelling was utilized to initiate ideas before construction where hard materials could be controlled and directed to take on the flexible, and revisions were much easier than by freehand. As both architects and fashion designers often work with similar 3D rendering and 3D scanning software, it follows that a similar aesthetic emerges. Using sophisticated computer technologies is liberating - designers can conjure forms that vary from mathematically complex multi-faceted engineering for futuristic spaces, to simple cubic or geodesic shapes that bring to mind natural entities. CNC systems allow an accuracy of cut and precise construction that beforehand would only be possible using an extremely high level of artisanal skill.

It could appear that information technology has gone beyond the physical. However, there is a strong return to the sense of touch, not by negating digital technologies, but by working alongside. Architects employ mathematical data modelling and space navigable computer environments, understanding that virtual 3D models help in the design process, but combine the digital with the creation of actual 
models. Likewise, in fashion the "toile" is a significant stage of the process, a physical preparation where decisions are made and editing takes place before the final outcome. By working directly with materials and allowing gravity to take effect, twodimensional flatness transmutes into fluidity where the rational becomes the organic.

Use of computer-aided technologies has enabled detailed laser-cut patterns where ideas of reveal and conceal are presented, while 3D printing is an example of complex additive manufacturing (AM) technology. A layered printing system, twodimensional deposits (often powder or liquid polymers) build to become threedimensional forms using fine layers that are measured in microns. As each slice is created it is fused and cured to solidify using an ultraviolet laser or lamp, before continuing to the next. The process used to involve unresponsive plastics but advances have allowed increased density variation in the raw material for more practical applications. A disadvantage of early 3D printing was time-consuming manufacture even for small-scale fashion accessories or architectural fittings. However, processing time has considerably speeded up and the possibilities are moving through the 3D printing of garments to the super-scale of entire buildings.

\section{Bespoke - Fit, Tailored to Suit and Exhibit}

Both clothing and buildings reflect the values that human beings hold dear those of personal, social, cultural, religious and political significance. They relate strongly to our psychological states and physiological requirements and house our aspirations for an improved, even utopian society. It is envisaged that in the near future commodities such as garments and buildings will be responsive to changing conditions for health/well-being, enabling the occupants to operate to their optimum.

The "Internet of Things" will affect our wardrobes and our surroundings by being hard-wired to pick up and respond to the minutiae of our changing needs; 
human bodies and contemporary cities are organisms that are in a constant state of growth (and decay). To manage these issues, "invisible" technologies can exist under the skins of buildings and within the fabric of our clothes - interiors and exteriors are ill-defined when roofs and ceilings retract or extend to be open to the elements or create closed spaces; in the same manner, sleeves roll up, seemingly of their own accord, when the temperature increases to ensure comfort to the wearer.

Le Corbusier famously created modernist housing that is often described as possessing a cold austerity, but his buildings were designed with great attention to human scale, proportion and need. His ideas of the way human beings interact with their immediate environments are now becoming reality. Socially driven, the work of Lucy Orta, who originally trained in fashion knitwear, is rooted in addressing the problems of society - dealing with issues of ethics, sustainability and ecology.

Frequently collaborating with her husband Jorge Orta, they create art installations and stage performances that reference the body. Lucy Orta has utilized her former fashion/textiles education to produce work that often transforms to meet the needs of the individual and the group. Her series 'Refuge Wear' and 'Body Architecture' date from the 1990s and show simple, portable structures/habitats. "Modular Architecture" and "Nexus Architecture," also from the 1990s, display individual body-based units as social sculpture that can be joined to make collective temporary dwellings, and public interventions that involve several participants. In her work a variety of materials is employed from traditional wools to high-performance synthetics with the latest finishing treatments - the "Habitent" series used aluminium-coated polyamide with folding carbon/aluminium structures. Lucy Orta's underlying message concerns the strength of communities and how working as teams can significantly make a 
difference. Paul Virilio is known for his ideas on technology and stated in his essay based on observations of her work during an interview, December 1995:

Packaging has a dual role, its prime role is to facilitate transport, and its secondary role is to facilitate the message. In Lucy Orta's work, clothes are no longer perceived as mere covering close to the body, as a second skin but also as a form of packaging, in other words, half-way between architecture and dress. (1996: 4/6 “Urban Armour”).

The expression of "self" and issues of identity are firmly rooted in textiles, fashion and architecture, albeit on different scales and ideas of "bespoke" and "tailor-made" in our future world will be democratic. A Savile Row suit is cut to flatter and correct imperfections, but it is expensive - financially and in time, with its necessary fittings. The future sees the ultimate in customisation where 3D scanning/modelling is set to influence our lives by creating tailored-to-fit clothing that we wear and custom-made buildings that we inhabit. These computer-based technologies can also allow for unique pieces by subtly changing the code to respond to customer demand.

And the catwalk/runway shows themselves, frequently staged at magnificent venues bring to mind the satirical fashion film Qui êtes-vous, Polly Maggoo? (1966), directed by William Klein that opens to a fashion show set in a church-like series of white caves. In the 1960 s there was a move away from the confines of the studio white walls and controlled environment to the streets, industrial settings or exotic locations. Consider the iconic architectural form, Le Palais Bulles (1989) by Antti Lovag on the French Riviera. This retro-futuristic villa with its cluster of bubbleshaped rooms is sand-/flesh-colored to blend into the landscape while the cellular forms are reputedly based on female curves. Bought by Pierre Cardin in 1992 it is used for fashion events including Raf Simons' Cruise 2016 collection for Dior. 
The three main shows of the fashion world that are often the most extravagant are Chanel, Dior and Louis Vuitton who compete for the most stunning locations at the most prestigious venues. Louis Vuitton's heritage is built on travel so such farflung locations seem particularly appropriate. The futuristic "spaceship" architecture of Bob Hope's home in Palm Springs (1973) by John Lautner was used as the backdrop for Nicolas Ghesquière's Cruise 2016 collection for Louis Vuitton. More futuristic allusions abound with Karl Lagerfeld's Cruise 2015 collection for Chanel staged at Zaha Hadid's Dongdaemun Design Plaza, Seoul (2013) where the curvilinear forms strongly relate to the human forms being viewed. Another setting for spectacular fashion shows is the Fondation Louis Vuitton (2014) by Frank Gehry who always approaches construction instinctively. This contemporary art museum/cultural center in Paris's Bois de Boulogne features twisted and curved glass for shapes that are lyrical and rhythmic, resembling the movement of a whale, a boat, sails in the wind or the muscles of a torso. It is in these environs that CEO Bernard Arnault often presents LVMH shows. The Niterói Contemporary Art Museum in Rio de Janeiro (1996) by Oscar Niemeyer, known for his daring forms, was the 'flying saucer' venue to showcase Louis Vuitton's Cruise 2017 collection.

Disciplines are blurred between the domains of fashion, architecture and art with the Mobile Art Chanel Contemporary Art Container (2010). Created by Zaha Hadid Architects, this unique collapsible space is intended as a site for art installations, specifically for Chanel and is inspired by a mobile object - Gabrielle "Coco" Chanel's iconic handbag. The continuous arch-shaped elements exist as two pods around a central courtyard and utilize the translucency of fiber-reinforced plastic as the façade cladding. This choice of material lends a delicate ethereality and allows light to softly penetrate the walls and ceiling, merging the inside with the outside. The 
exterior skin is made of reflective materials that can be tailored to differing programmes and illuminated in a variety of colors. The curvilinear steel-built construction with aluminium extrusions is mobile and ephemeral - it can be built or decommissioned in one week proving its functionality and versatility.

\section{Conclusion}

A blending of practicality/physicality with the visionary/virtual aligns with William Gibson's ideas of the breakdown of ambiguity where our imaginations are left in an undefined state of being and actuality. It would appear that architecture is moving towards a fluid state and fashion is taking on the architectonic. Jacques Derrida was interested in how language can be broken down - the opposition of boundaries where contrasts are needed to more deeply understand, and where the open-ended and the transferable are deciphered (Attridge, 2004). To this effect, today's intelligent buildings offer screen-based platforms for immersive and interactive environments where such boundaries are indistinct, blurred and frayed. Responsive and transformable, they are information-based to reveal a new era of "genetic architecture" for an increasingly mobile society. In turn, the acme of fashion demonstrates the human form in vital and dynamic expressions.

In the future it is anticipated that the worlds of textiles, fashion and architecture will become further de-compartmentalized to share territories. Crossfertilisation will be encouraged, overlaps celebrated and the thinking of tomorrow will bring together different minds and different approaches for hybrid practices. Interactions will flourish and on-going dialogues continue and deepen, where the grounding of engineering will work with the imagination of artistic thinking.

In appraising the relationships between textiles, fashion and architecture it is demonstrated that anatomical and topographical perspectives are rethought and reused 
in divergent ways while pertaining to human scale and proportions. It is envisaged that such a view will only endure to give resonance and poignancy to our most intimate design solutions - where the science of architecture meets the craft of textiles that meets the intuition of fashion.

\section{References}

Artic.edu. ca. 2016. Form follows Function. Accessed 31 December 2016

http://www.artic.edu/research/louis-sullivan-collection

Attridge, Derek and Thomas Baldwin. 11 October 2004. Jacques Derrida. Obituary. Accessed 6 March 2017.

https://www.theguardian.com/news/2004/oct/11/guardianobituaries.france

Balmond, Cecil. 2007. Element. Munich, London and New York: Prestel

Benedikt, Michael.1992. Cyberspace: First Steps. Cambridge, MA: MIT Press

Blaisse, Maria - Projects. 2008. Bamboo; 2007-2008. Moving Meshes; 2005-2007. Gauze

Forms. Accessed 28 December 2016. http://www.mariablaisse.com/maria/home.html

Boudicca - History. 2005-2006. The Invisible City - AW:06. Accessed 30 December 2016

http://www.platform13.com/pages/history/invisible_content.html

Bourdieu, Pierre. 1987. Distinction: A Social Critique of the Judgement of Taste. Cambridge,

MA: Havard University Press

Cunningham, Bill. September 1989. The Collections. New York: Details

Cunningham, Bill. March 1990. Fashion de Siècle. New York: Details

Driessen + van Deijne. 2014. The Beacon of Ezinge. Accessed 30 December 2016

https://www.behance.net/gallery/20560781/The-Beacon-of-Ezinge-

Hodge, Brooke, Patricia Mears and Susan Sidlauskas. 2006. Skin + Bones: Parallel Practices

in Fashion and Architecture. London and New York: Thames \& Hudson

Levine, Donald N. and Georg Simmel. 1972. Georg Simmel on Individuality and Social

Forms. Chicago, Il: The University of Chicago Press 
Lévi-Strauss, Levi. 1966. The Savage Mind (English language version of the 1962 La Pensée Sauvage). Chicago, Il: The University of Chicago Press

Liminal - Portfolio. 2010-2011. Organ of Corti. Accessed 28 December 2016

http://www.Li.org.uk/portfolio/organ-of-corti/

Mies Society. ca. 2016. Less is More. Accessed 31 December 2016

http://www.miessociety.org/legacy/

Sudjic, Deyan. 1990. Rei Kawakubo and Comme des Garçons. London: Fourth Estate and Word Search Publishing in conjunction with Blueprint Magazine

Tanizaki, Jun'ichirō. 1977. In Praise of Shadows. Stony Creek, CT: Leete's Island Books (translation into the English language by Thomas J. Harper and Edward G. Seidensticker and first published in the December 1933 and January 1934 issues of Keizai Ōrai)

Venturi, Scott Brown. ca. 2016. Less is a Bore. Accessed 31 December 2016

http://venturiscottbrown.org

Virilio, Paul, Jérome Sans, Jean-Michel Ribettes and Philippe Piguet. 1996. Refuge Wear Lucy Orta. Paris: Éditions Jean-Michel Place

\section{Figure captions:}

Figure 1. Maria Blaisse. 'Gauze Spiral'. From the series 'Gauze Forms', 20052007, that uses polyester, a versatile synthetic material to create flexible geometrics where one form can become many through structural articulation. This spiral-based configuration explores concepts of interior and exterior. Photograph by Joost Guntenaar. Reproduced by permission of Maria Blaisse. Figure 1 to accompany the text Introduction on page 2. 
Figure 2. Driessen + van Deijne. 'The Beacon of Ezinge'. 2014. Digitally printed glass on two façades of the tower in the community buildings. This tower stands out like a beacon, looking out over the surrounding complex. Architects - Atelier PRO. Photograph by Maarten Noordijk. Reproduced by permission of Driessen + van Deijne.

Figure 2 to accompany the text Facades, Cladding, Skins on page 6.

Figure 3. Driessen + van Deijne. 'The Beacon of Ezinge'. 2014. The original design for the digitally printed glass façades. The sophistication of the process allows a faithful rendering of the initial drawing with its saturated colors and mix of geometric and organic forms. Photograph by Michiel Vijselaar. Reproduced by permission of Driessen + van Deijne.

Figure 3 to accompany the text Facades, Cladding, Skins on page 7.

Figure 4. Liminal. 'Organ of Corti'. 2010-2011. A lattice of acrylic cylinders is positioned in a 'sonic crystal array' to accentuate and attentuate the noise frequencies occurring in the surroundings - here, overlooking the M6 in Cumbria, UK. The listener is immersed in this built installation and can focus on the real sounds that will vary depending on their actual position within the work. Photograph by David Prior. Reproduced by permission of Liminal.

Figure 4 to accompany the text Temporal, Ephemeral V Monumental, Permanent on page 10. 
Figures 5 and 6. Boudicca. 'The Invisible City'. A/W 2006. This ready-to-wear collection has the monochrome starkness of black and white for sculptural forms that simultaneously reference the femininity of ballet tutus and the masculinity of much contemporary architecture. Photographs by Bumble \& Bumble - Michael Gordon's team. Reproduced by permission of Boudicca.

Figures 5 and 6 to accompany the text Materials, Technologies - Analog + Digital on page 16.

Figure 7. Maria Blaisse. 'Breathing Bamboo'. Dance improvisation performed at the cultural center, Designhuis, Eindhoven, the Netherlands in 2012. From the series 'Moving Meshes', 2007-2008, this work shows the inter-relationship between the human body and the created forms where an open sphere is the starting point for many variations. Photograph by Loan Oei. Reproduced by permission of Maria Blaisse.

Figure 7 to accompany the text Materials, Technologies - Analog + Digital on page 18. 